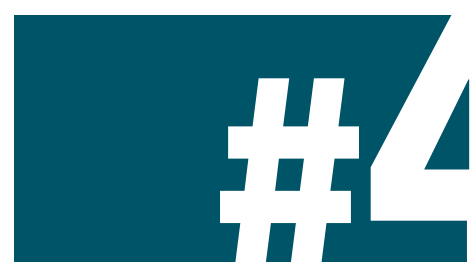

ESPECIAL AMÉRICA LATINA

\title{
O LADO HUMANO DA INTEGRAÇÃO
}

A INTEGRAÇÃO REGIONAL NA AMÉRICA LATINA EXIGE URGEN-

TES POLÍTICAS PÚBLICAS ORQUESTRADAS ENTRE OS DIFEREN-

TES PAÍSES, EM ÁREAS COMO SEGURANÇA, EDUCAÇÃO, SAÚdE,

CIDADANIA E DIREITOS HUMANOS. AINDA EXISTEM ENORMES

PENDÊNCIAS NA FORMULAÇÃO DESSAS POLÍTICAS

ANA CRISTINA BRAGA MARTES, professora da FGV-EAESP, ana.martes@fgv.br VÍTOR AUGUSTO POSSEBOM, graduando pela FGV-EESP, vitor.possebom@gvmail.br

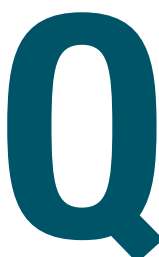

uando se discute a integração entre os países latinoamericanos, geralmente $\mathrm{o}$ tema é analisado pelo ângulo econômico. O lado social ou humano - do qual fazem parte questões relacionadas a fluxos migratórios, conflitos fronteiriços, cidadania e políticas sociais - raramente é abordado com a profundidade devida. Neste artigo, procuramos discutir a integração regional entre países latino-americanos a partir dessa ótica, chamando a atenção para a necessidade de políticas regionais coordenadas que levem em conta o respeito aos direitos humanos e uma abordagem multicultural.
Dois problemas, em particular, demandam atenção urgente dos diferentes governos nacionais e um esforço de orquestração de políticas: a questão fronteiriça e as condições de vida dos migrantes em grandes centros urbanos.

\section{FRONTEIRAS}

Há diversas regiões de fronteira entre países latino-amenricanos que apresentam conflitos, violência e outras situações críticas. É o caso da tríplice fronteira entre Brasil, Argentina e Paraguai, onde é comum o contrabando de mercadorias e há suspeitas de tratar-se de região que abriga terroristas. Fronteiras amazônicas são também marcadas por 
problemas como garimpo clandestino, tráfico de drogas e ação guerrilheira. Por fim, a ocupação de terras paraguaias e bolivianas por fazendeiros brasileiros, apesar de sua importância econômica, também tem sido causa de conflitos.

Contrabando e tráfico - de armas, de drogas e de pessoas - são comuns nas áreas de fronteira, locais de atuação de organizações criminosas. As Forças Armadas Revolucionárias da Colômbia (FARC) apresentam sinais de internacionalização, aliando-se ao Exército Revolucionário do Povo (ERP), do Paraguai, que por sua vez também possui vínculos com grupos criminosos brasileiros. Outro problema relevante diz respeito à ocupação de terras, refletindo-se em recentes conflitos relacionados à presença de garimpeiros brasileiros na região de Altamira, no Suriname, e também em embates entre os governos boliviano e paraguaio e fazendeiros brasileiros que detêm terras nas fronteiras desses países com o Brasil.

\section{CIDADES}

Não apenas as regiões de fronteira, mas também os centros urbanos, merecem atenção. $O$ exemplo mais emblemático dos problemas nas cidades é a presença de um grande contingente de imigrantes bolivianos residindo em São Paulo e trabalhando em condições de semiescravidão. Os principais motivos que levam sul-americanos a emigrarem para o Brasil são de ordem política (ditaduras e guerrilhas) e econômico-laboral.
O maior contingente de imigrantes corresponde aos bolivianos, estimados em 80 mil pelo Ministério da Justiça brasileiro, e em 250 mil pelo boliviano CEDLA - Centro de Estudios para el Desarrollo Laboral Agrario.

A maior parte dos bolivianos residentes em São Paulo trabalha em tecelagens nos bairros do Brás e Bom Retiro, onde executam jornadas que começam às $8 \mathrm{~h}$ e não terminam antes das $21 \mathrm{~h}$, recebendo valores ínfimos por peça produzida e morando nas próprias fábricas. As condições indignas de trabalho e moradia atuam como fator desencadeante de outros problemas, entre os quais violência doméstica, gravidez na adolescência, alcoolismo e depressão, esta última causada pela desilusão encontrada na "terra das oportunidades". Como agravante, é possível citar ainda a inexistência de previdência social para esses imigrantes, o abandono da escola e péssimas condições de saúde, havendo suspeitas (embora não existam dados consolidados) de que o número de infectados por tuberculose nessa população é superior à média paulistana.

\section{POLITICAS CORRENTES}

O enfrentamento desses problemas exige a formulação de políticas públicas específicas, voltadas à questão migratória e à segurança, bem como a questões sociais internas de cada país. O Brasil tem procurado executar algumas dessas políticas, parte delas em conjunto com outros países sul-americanos.
No campo dos direitos humanos e sociais, é importante destacar a Constituição Federal de 1988, que garante a igualdade entre brasileiros e estrangeiros residentes no país, implicando a obrigação do Estado de garantir aos migrantes o atendimento de direitos constitucionais básicos como os de moradia, alimentação, saúde e previdência. É dever legal do Estado brasileiro, desta forma, garantir condições de vida adequadas aos bolivianos residentes em São Paulo.

Percebe-se um esforço prático nesse sentido, no Acordo Brasil-Bolívia firmado em setembro de 2005, que estabelece meios mais fáceis de regularizar a situação legal de imigrantes em ambos os países. Este acordo já gerou alguns frutos positivos, como, por exemplo, o fato de crianças bolivianas moradoras no bairro do Brás estudarem em escolas públicas da região.

Outra medida importante adotada pelo Brasil foi a aprovação da Lei $n^{\circ}$ 9.474/97. Esta, além de instituir o Comitê Nacional para Refugiados (CONARE), ratifica o compromisso brasileiro de defesa dos direitos humanos e proteção dos refugiados por meio de políticas públicas que objetivem inseri-los na sociedade e no mercado de trabalho.

Finalmente, no campo específico da segurança pública, o Brasil tem procurado executar políticas integradas com seus vizinhos, haja vista que esta é, provavelmente, a única forma de superar 
problemas complexos e severos como o narcotráfico. Destacam-se nessa área a cooperação militar e de inteligência entre Brasil e Colômbia no combate às FARC. Recentemente, também foram firmados com o Paraguai acordos de cooperação no combate ao tráfico.

\section{DESAFIOS}

Apesar desses evidentes esforços, ainda se verificam grandes falhas e lacunas nas áreas de educação, saúde e regulação trabalhista. Faltam escolas bilíngues nas fronteiras, e muitos imigrantes temem utilizar hospitais por falta de documentação. Essa ausência de identificação legal também é, em parte, responsável pelos flagrantes desrespeitos à legislação trabalhista brasileira. Para se resolver essa situação, ainda se faz necessário agilizar o processo de tramitação da legalização do migrante, facilitar a comprovação de entrada e trabalho e reduzir o custo de aquisição dos documentos necessários aos procedimentos.

Para dar andamento às pendências, alguns encaminhamentos são necessários. O primeiro é a ampliação das campanhas educativas dos direitos trabalhistas nas comunidades de migrantes. Depois o combate ao trabalho escravo e à exploração sexual. O terceiro é o estímulo às cooperativas de migrantes, medida que tanto enfrenta as situações de exploração servil quanto possibilita o desenvolvimento econômico da comunidade. O quarto é a facilitação do acesso à saúde pública, à

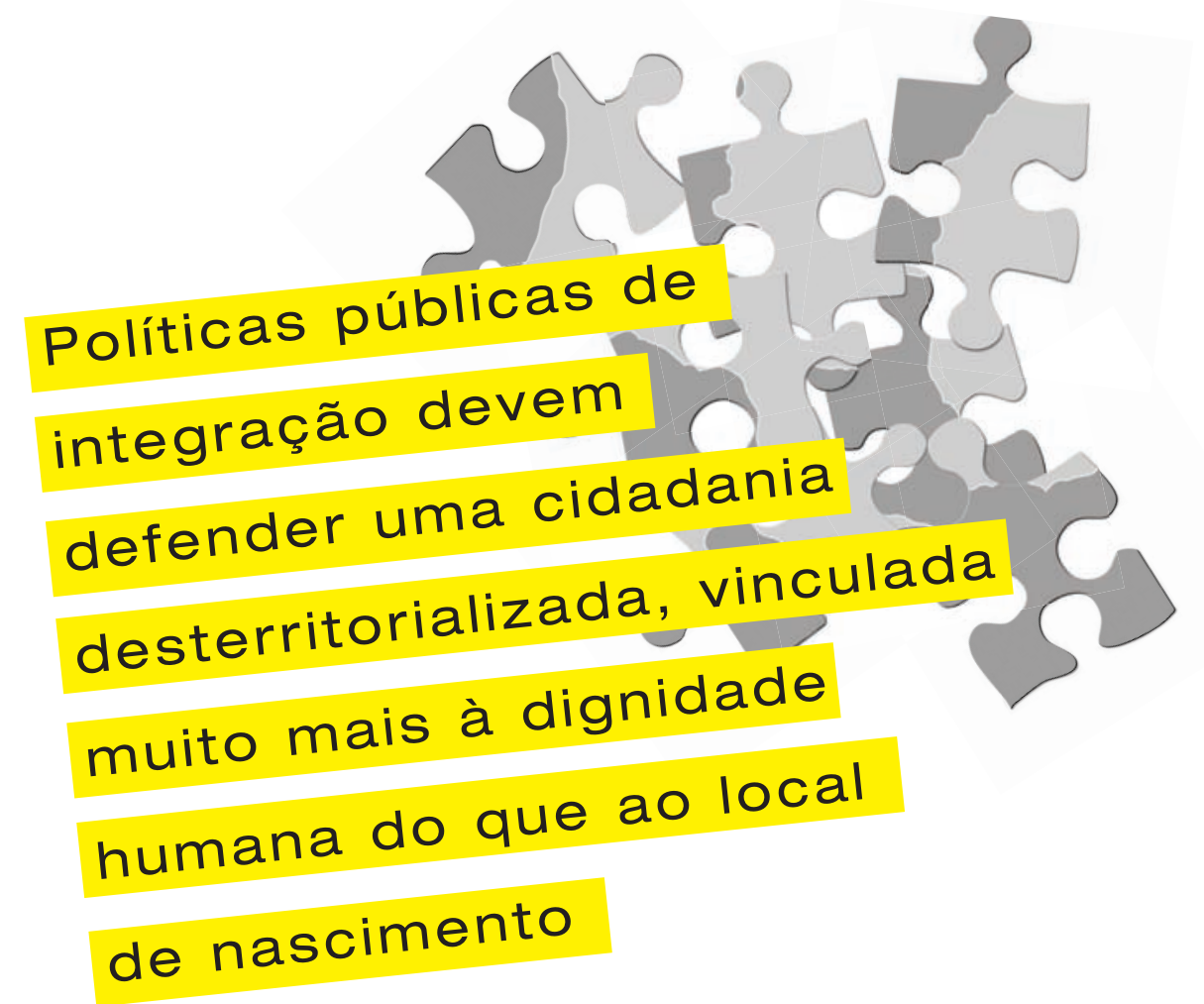

educação bilíngue e à previdência. $\mathrm{O}$ quinto é a simplificação do processo de envio de remessas aos países de origem - inclusive para que essas transferências possam ser usadas como forma de combate à pobreza e desenvolvimento regional nas áreas mais pobres do continente. Por fim, a livre circulação de pessoas e de trabalhadores no Mercosul é uma medida que se faz premente.

Tais encaminhamentos devem ser pautados por uma abordagem multicultural de políticas públicas, que caminhe em direção à proteção e à ampliação dos direitos sociais e políticos do migrante; à facilitação da inserção do migrante no país de destino e ao estímulo à manutenção de suas relações com seu país de origem. Cooperação internacional e respeito ao pluralismo político, cultural e religioso devem pautar as medidas de política. Em resumo, uma adequada política pública deve aspirar a construir e a defender uma cidadania desterritorializada, isto é, vinculada à dignidade do indivíduo e não apenas ao seu território de nascimento ou pertencimento familiar.

O quadro apresentado exige, de um lado, a cooperação entre os Estados em políticas de combate às diversas formas de tráfico (drogas, armas e pessoas). De outro, exige a evolução e integração das políticas públicas internas dos diferentes países. Tal integração interna é fundamental para garantir efetivamente ao migrante direitos sociais como saúde, educação e previdência. 